\title{
CDISC SEND Version Terminology
}

National Cancer Institute

\section{Source}

National Cancer Institute. CDISC SEND Version Terminology. NCI Thesaurus. Code C89982.

The terminology that includes concepts relevant to the Clinical Data Interchange Standards Consortium (CDISC) Standard for the Exchange of Non-clinical Data (SEND) versioning information. 